\author{
University of Texas Rio Grande Valley \\ ScholarWorks @ UTRGV
}

Counseling Faculty Publications and

Presentations

College of Education and P-16 Integration

2017

\title{
Compassion and Self-compassion: Conceptualization of and Application to Adjustment to Disability
}

\author{
Susan Stuntzner \\ The University of Texas Rio Grande Valley, susan.stuntzner@utrgv.edu
}

Follow this and additional works at: https://scholarworks.utrgv.edu/coun_fac

Part of the Counseling Commons

\section{Recommended Citation}

Stuntzner, S. (2017). Compassion and Self-compassion: Conceptualization of and Application to Adjustment to Disability. Journal of Applied Rehabilitation Counseling, 48(2). https://doi.org/10.1891/ 0047-2220.48.2.15

This Article is brought to you for free and open access by the College of Education and P-16 Integration at ScholarWorks@ UTRGV. It has been accepted for inclusion in Counseling Faculty Publications and Presentations by an authorized administrator of ScholarWorks@ UTRGV. For more information, please contact justin.white@utrgv.edu,william.flores01@utrgv.edu. 


\title{
Compassion and Self-compassion: Conceptualization of and Application to Adjustment to Disability
}

\author{
Susan Stuntzner
}

\begin{abstract}
For many, disability may ignite feelings of grief, sadness, loss, and/or emotional pain. Others discover they harbor negative or self-critical thoughts and beliefs (i.e., blame) which compounds and complicates the personal coping process. Adjustment to disability models exist to help persons with disabilities and professionals understand or explain their negative thoughts, feelings, and experiences; yet, they do not overtly discuss or address emerging skills and approaches such as compassion and selfcompassion as a part of the disability adjustment process. In an effort to change this trend, an eclectic theoretical model which infuses self-compassion and compassion-based techniques has been developed. Rehabilitation counselors are provided with an explanation of the ways existing research on compassion and self-compassion can be used to strengthen their application to the adjustment needs of persons with disabilities. Information about how to incorporate compassion and self-compassion into the rehabilitation counseling adjustment process and recommendations are also provided. Keywords: compassion, selfcompassion, grief, loss, counseling approaches, cognitive behavioral therapy, person-centered therapy, disability, adjustment to disability
\end{abstract}

A djustment to disability is an important part of the rehabilitation counseling process. Whilst, it is hoped that persons with disabilities will eventually adjust to their disability and the associated life changes that follow, adjustment to disability is not something that necessarily happens for all people, given enough time. For some, learning to cope and adjust to the disability is painful, difficult, and arduous at best. It is a process that has often been associated with the recognition and willingness to address and work through negative thoughts, feelings, and experiences, some of which may include feelings of grief or loss (Wright, 1983). Similarly, successful adjustment has been explained as a non-linear process, one with potential setbacks when negative events occur or reoccur (Livneh \& Antonak, 1997). Still other disability scholars, promote the idea of "teaching" persons with disabilities about their disability (Trieschmann, 1980, 1988) so they can make informed decisions about how to live with their disability.

Such approaches are of tremendous value, but they do not consider the spiritual aspect or the active cultivation of skills that can be learned, enhanced, and integrated throughout a person's life to effectively cope with the disability, hurtful situations, and events that happen because of disability. Existing approaches theoretically explain what might occur during the adjustment to disability process or suggest the need to view oneself in a different way (Wright, 1983), but they don't (a) promote or teach persons with disabilities self-soothing skills (Neff, 2011), (b) recognize self-inhibiting behaviors (i.e., self-criticism; Gilbert, McEwan, Matos, \& Rivis, 2011), or (c) assist persons with disabilities in understanding that they are not alone in their painful experience. Nor, do they help persons with disabilities discover and learn they have a choice in whether or not they will face their mental and emotional pain with kindness, patience, forgiveness, and compassion or become consumed with anxiety, fear, and depression (Feldman \& Kuyken, 2011).

Compassion and self-compassion are two research constructs and approaches that are newer, may be infused into the adjustment to disability process, and have been studied empirically to aid in reducing negative thoughts, feelings, and behaviors and promote positive ones. To date, little information has been considered or explored about these constructs as a part of the rehabilitation counseling profession (see Grover, 2015; Stuntzner, 2014). Nonetheless, much of the preliminary research suggests that the cultivation and practice of compassion-based behaviors and techniques (i.e., self-compassion, compassion for others) would align well with many of the goals related to adjustment to disability and successful coping. Therefore, following a review on grief, loss, and change and adjustment to disability models, this article assists rehabilitation counselors in understanding how compassion and self-compassion are separate and different from well-known terms such as adjustment and acceptance, conceptualizing the ways compassion and self-compassion can be incorporated into counseling approaches, and in learning an eclectic approach to counseling 
while integrating these constructs. Additionally, rehabilitation counselors are provided information about the research on compassion and self-compassion to help support and understand their potential relevance to dealing with grief, loss, difficult thoughts, and feelings and to the adjustment to disability process. The latter sections discuss strategies for implementation and professional implications.

\section{Grief and Loss Following Disability}

Disability is a situation typically associated with many changes in a person's life and several of these are unanticipated or unforeseen (Stuntzner, 2014). Changes and life alterations due to disability are a source of grief and loss for many persons with disabilities. In these instances, grief and loss resembles deep sadness, sorrow, despair, anger, helplessness, and/or mental and emotional distress (Raphael, 1984). For some, such thoughts and feelings may be related to the fact that a disability is present and there has been a loss or change in personal functioning and capabilities (Stuntzner, 2015). Similarly, some people may perceive that life can never be as it was before the disability or as it was hoped to be (Elders, 1995). Others may experience intense feelings of grief and loss related to the obvious, notable, and undesired changes that sometimes accompany disability such as loss of the person one used to be, relationships and friendships, companionship and intimacy, life dreams, financial well-being and resources or access to them, personal autonomy and independence, purpose or meaning in life, or employment (Stuntzner, 2015). Further, persons with disabilities may experience emotional and psychological difficulties as they learn about and try to deal with societal, attitudinal, and environmental barriers, stigma, bias, strained interpersonal reactions (Siller, Chipman, Ferguson, \& Vann, 1967; Smart, 2009), poor treatment from others, as well as changes related to their self-concept or self-esteem.

Drastic life changes have the potential to affect people in such a way that their previously held beliefs and assumptions about life and the world are shattered (Murray, 2001) or need to be altered (Parkes, 1988) for successful coping to occur. Persons with disabilities who perceive the world as unpredictable and unsafe (Murray, 2001), therefore uncontrollable, may compound the adjustment to disability process by holding such perceptions as these may generate additional fear and anxiety. People who are critical of themselves or others or who have a negative orientation towards the acquisition and meaning of disability may be further challenged in their ability to cope with and move past the disability.

Additionally, factors such as perceived blame, whether it is self-blame or blame towards others, has been discussed throughout the literature as having an inherent impact on the coping and adjustment to disability process (Buckelew, Baumstark, Frank, \& Hewett, 1990; Nielson \& MacDonald, 1998). For instance, some researchers stress that blaming oneself for a loss (Cutrona, 1993) and others for their predicament (Tennen \& Affleck, 1990) contributes to greater amounts of personal distress and grief. Whilst coping with grief and loss is not easy, it is evident for some individuals that coping with negative thoughts and feelings associated with disability and stressful life changes following disability may be ongoing, reoccurring, and present for a long time (Teel, 1991). As a result, it is important that persons with disabilities learn how to better face, address, and work through their deeply held thoughts and feelings so they can experience rather than suppress them.

\section{Adjustment to Disability Models Used to Address Adjustment to Disability}

Grief and loss are a normal part of life (Murray, 2001); for most, it is an experience that people will encounter throughout their life time. Disability adjustment scholars have developed models (i.e., early psychological models, stage models, educational models, ecological models), which are familiar to most rehabilitation counseling professionals, about how some persons with disabilities experience a sense of loss, mourn, and/or proceed through negative thoughts and feelings as a part of their adjustment to disability process (Livneh \& Antonak, 1997; Wright, 1983).

Models developed by Wright (1983) and Livneh and Antonak (1997) stress that people with disabilities may experience some sort of loss, grief, and/or negative emotions as a part of the coping and adaptation process and that such feelings are essential components of the healing process as people work their way towards more positive adaptation. Wright (1983) indicates that people can face their loss through mourning followed by learning to make positive changes in how a person views oneself, the disability, and personal values. Livneh and Antonak (1997) posit that adjustment to disability is a process and not necessarily a linear one where persons with disabilities experience negative thoughts and feelings (i.e., shock, anxiety, denial, depression, internalized anger, externalized hostility) while they are attempting to learn how to adjust to the disability in a more positive manner (i.e., acknowledgement, adjustment). These scholars indicate that the coping and adaptation process is individualized and likely to vary from person-to-person and that adjustment to disability may be affected by factors such as age of onset, personality differences, beliefs and attitudes, finances, and so forth.

Other disability scholars have tried to explain adjustment to disability as something that occurs with the aid of education about the disability and factors that affect the coping process (Trieschmann, 1980, 1988) or as that which is affected by environmental events (Scofield, Pape, McCracken, \& Maki, 1980). Trieschmann $(1980,1988)$ indicates that education about the disability can help persons with disabilities improve their coping process. Such educational approaches can assist people in learning about the disability, factors that may affect the coping process, and environmental situations and changes encountered once they are in the community. Scofield and colleagues (1980) take a different approach to adjustment. These scholars state that a person's adjustment process is influenced by the environmental events and components that surround a person. People (i.e., families, employers), agencies, (i.e., human service and counseling agencies), and other external forces (i.e., policies, legislation), have a role in placing expectations on persons with disabilities about how they are to meet societal standards. These standards and expectations may not be the same and conflict with one another. Nonetheless, persons with disabilities oftentimes absorb these messages which then influence how they adjust to their disability and set of circumstances. 
Whilst these models have value in addressing parts of the adjustment to disability process and in aiding rehabilitation counseling professionals in understanding the adjustment to disability process, they do not appear to recognize or overtly state the need for active approaches such as teaching persons with disabilities emotional and mental coping skills (i.e., self-compassion when other people treat them in a hurtful or offensive manner, forgiveness of self or others, resilience cultivation skills), self-soothing skills (i.e., calming oneself when they are upset or anxious), and compassion and self-compassion strategies (i.e., acceptance of self as being imperfect, recognition that everyone knows emotional and mental pain, meditation, visualization, gently facing and dealing with grief, loss, and strong emotions) as a part of the adjustment to disability process. Further, with the exception of Livneh and Antonak's (1997) stage model, most of these do not clearly identify the relationship held between a person's thoughts, feelings and behaviors.

\section{Differentiation of Terminology: Compassion as a Different Component of Adjustment}

Rehabilitation counseling professionals wanting to better understand the utility of compassion and self-compassion as a part of the adjustment to disability process may find it helpful to differentiate these and related terms (i.e., forgiveness) from well-known words such as acceptance and adjustment. Acceptance refers to the idea that something, in this case the disability, is present, real, and is not expected to dissipate or disappear. Adjustment to disability models often stress the notion that when persons with disabilities can accept the reality that they have a disability and its associated limitations or changes, they are demonstrating signs of improved coping and making progress towards adjustment. Adjustment is a term often associated with the final stage of adaptation to disability (Livneh \& Antonak, 1997). It is at this time in the coping process where persons with disabilities fully understand that the condition is permanent, make adjustments in their life based on the disability, set new personal and life goals, and work on community integration and independence.

Whilst understanding these terms are important and essential, other terms, behaviors, and approaches are also of value (i.e., forgiveness, compassion, self-compassion) in relation to the coping and adaptation process. Terms and behavioral approaches such as forgiveness, compassion, and self-compassion are separate but inter-related to each other and perhaps different processes from acceptance and adjustment. Forgiveness refers to the recognition of negative thoughts and feelings following the presence of a deep personal hurt or offense so that these can be addressed as a part of the healing process. Following the recognition of negative thoughts and feelings, people are afforded the opportunity to view the person or situation in a more caring, tolerant, and compassionate way so that the offended person can replace the inner hurt with neutral or more positive thoughts and feelings (Enright, 2001; Enright, Rique, \& Coyle, 2000). Compassion refers to the person's ability to extend love, kindness, peace, warm thoughts, tolerance, and generosity toward others (i.e., a friend, relative, or a stranger; Makranski, 2012; The Dali Lama, 2003). Self-compassion is the ability to be kind, loving and accepting of oneself when a person is experiencing emotional, psychological, physical, or spiritual pain (Neff, 2011).

Upon closer examination, it may appear that these terms are related and components of the other. For example, to forgive, people may need to become more compassionate or develop self-compassion; thus, people may find it helpful to first recognize when they are compassionate towards others (Germer \& Neff, 2013) so they can give themselves permission to offer and cultivate it within themselves.

Despite their interconnectedness, rehabilitation counseling professionals need to recognize these skills do not occur automatically as a part of the adjustment to disability process and that they can be taught, learned, and cultivated as therapeutic techniques to effectively address personal and interpersonal hurts and offenses (Enright, 2001; Germer \& Neff, 2013; Neff, 2011). Additionally, they are skills which require action on the part of the hurt or offended individual, as it is this person who is asked to consider his or her current emotional and mental functioning and ways in which it is inhibiting them from thinking, feeling, and behaving in more positive ways. Related is the notion that with forgiveness, compassion, and self-compassion, people can decide if they will turn towards and face their pain and use the experience as a catalyst for positive growth (Neimeyer, 1999) or to find meaning and purpose (Park, 2010). Once these skills are learned they can be integrated and applied to future hurts and offenses or to reoccurring ones (i.e., self-blame for disability, lack of acceptance, societal bias and negative attitudes; Buckelew et al., 1990; Nielson \& MacDonald, 1998; Siller et al., 1967; Smart, 2009). Alleviation of such hurt can improve the coping and adaptation experience.

\section{Compassion and Self-compassion: An Eclectic Theoretical Counseling Approach}

Compassion and self-compassion can be helpful in assisting persons with disabilities and rehabilitation counseling professionals in recognizing, facing, and addressing grief and loss, negative thoughts and feelings, as well as deep hurts and offenses - all of which are often interrelated to the other and often a part of the adjustment to disability process. Rehabilitation counseling professionals wanting to teach these skills as a part of the adjustment to disability process may find it beneficial to conceptualize how they relate to well-known approaches such as Person-centered Theory and Cognitive Behavioral Theory followed by the ways self-compassion can be approached and taught along with an eclectic approach that can assist in helping persons with disabilities cope with grief, loss, and change following disability.

\section{Person-centered Therapy}

Person-centered Therapy is a theoretical approach that focuses on the development of a caring and unconditionally accepting relationship between the individual and the counselor, demonstrates respect for peoples' values, and is considered emotionally supportive rather than directive (Cott, 2004). Person-centered Therapy emphasizes each person's growth potential, their ability to self-actualize, and to heal themselves when specific therapeutic conditions are provided and cultivated throughout the 
counseling relationship (Jones-Smith, 2016b). Further, it is an approach that allows people to be accepted "just as they are" while they learn to discover themselves and develop into the person they desire to be; it does not label, judge, or diagnose (Cott, 2004). This is an important feature given the various negative experiences of many persons with disabilities.

Several aspects of Person-centered Therapy can be enlisted to understand the cultivation of compassion and self-compassion amongst persons with disabilities. Rehabilitation counselors can use Person-centered Therapy to develop a trusting, safe, genuine, caring, and unconditionally accepting therapeutic relationship with persons with disabilities. Such a relationship may be the first means of demonstrating and modeling compassion to the individuals served and can be essential to persons with disabilities who feel judged, shamed, angry, self-critical, stigmatized, hopeless, isolated, hurt, and grief-stricken (Elliott, Watson, Goldman, \& Greenberg, 2004; Goffman, 1963; Reeve, 2002). Demonstration and compassion-modeling strategies are essential for personal healing and adjustment, particularly given the fact that many persons with disabilities receive negative messages about themselves, their worth, value, and capabilities from others and society (see Stunzner, 2014). Some of these negative messages are very hurtful, become internalized, and hold great power in determining how persons with disabilities view themselves (Smart, 2009; Stuntzner, 2012). As a result, some persons with disabilities may not know how to be compassionate towards themselves or others because of their current or repeated history of negative experiences.

Second, as person with disabilities recognize compassion that is extended to them, many feel safe and secure, so much so that the compassion extended creates an environment and professional relationship through which they can explore their thoughts, feelings, and behavioral choices. For example, persons with disabilities may discover how nice it feels to be accepted, valued, and emotionally supported which may be quite different than how they are either currently treating themselves or how they have been treated by others. In other words, the compassionate counseling relationship creates an environment through which persons with disabilities can consider questions or ideas: How do I treat myself most of the time? Am I kind, loving, tolerant, and forgiving of myself when I experience hurt, loss, and emotional pain or am I critical and judgmental towards myself? Have I absorbed other peoples' negative perceptions of and treatment towards me in ways that affect my ability to extend compassion toward myself and others? If I were to make intrapersonal changes and become more compassionate towards myself and others, what would that look like?

Third, through the personal reflection and discovery process, person with disabilities may learn to recognize they are not acting or making choices that are congruent with themselves, their values, and personal goals. Persons with disabilities may realize they are not as kind, tolerant, and loving towards themselves or other as they would like to be. Some may discover they are not being emotionally supportive and respectful towards themselves when they are hurting or undergoing emotional strife. Such realizations can create a heightened sense of self-awareness and assist persons with disabilities in discovering they are not behaving in compassionate or self-compassionate ways, although there is a strong innate desire to be more congruent between their desires and their reality. Incongruence in peoples' experience and promotion of compassion and self-compassion becomes the catalyst for personal change, because persons with disabilities realize they want to help themselves be more compassionate and self-compassionate so they can learn to meet their own personal and intrapersonal needs with kindness, love, tolerance, and genuineness rather than continue in ways that have not helped them.

Fourth, another component worthy of consideration is unconditional positive regard. Unconditional positive regards refers to the ability of someone being able to accept another, completely and without specific conditions being met (Jones-Smith, 2016b). Unconditional positive regard from the counselor is an important part of the compassion-cultivation process. Persons with disabilities who are considering the relevance and perhaps the need for compassion and self-compassion cultivation as a part of their life are likely to make mistakes and can be assisted by knowing they are accepted by the counselor when they occur. Compassion cultivation strategies take practice, occur over time, and are not a quick fix that work instantaneously (Gilbert, 2009). Nonetheless, persons with disabilities can learn to be more compassionate towards oneself and others with continued awareness and practice.

\section{Cognitive Behavioral Therapy}

Cognitive Behavioral Therapy is an effective approach in helping persons with disabilities recognize their thoughts, feelings, and behaviors; cope with mood disorders and difficulties (see Swett \& Kaplan, 2004); and reduce negative emotions such as anxiety and depression (Bruce, Spiegel, \& Hegel, 1999; JonesSmith, 2016a) which are common emotions among many persons with disabilities. Cognitive Behavioral Therapy is a theoretical approach that stresses the importance of the counseling relationship, similar to Person-centered Therapy, indicates a strong professional relationship is essential and that counseling professionals must be empathetic and promote unconditional positive regard throughout the working relationship (Beck, 2005; Tursi \& Cochran, 2006). Cognitive Behavioral Therapy states that counselors should "treat the people they work with how they themselves would like to be treated" (Beck, 2011, p. 18). Cognitive Behavioral Therapy promotes that peoples' thoughts, feelings, and behaviors are interrelated and affect one another. Related is the idea that it is not the events that happen to people but their interpretations of them that influence how they think, feel, and respond (Beck, 2011). According to this approach, when people learn to change their thoughts and beliefs, their perception of and reaction to the situation and that which they feel also changes (Beck, Rush, Shaw, \& Emery, 1979).

Several components of Cognitive Behavioral Therapy can be used to integrate the use of compassion and self-compassion as a part of the grief, loss, and adjustment to disability process. More specifically, Cognitive Behavioral Therapy can promote these two constructs through (a) the counseling relationship; (b) collaborative goal setting; (c) educational exercises about the relationship between a person's, thoughts, and feelings; (d) recognition of negative thoughts and feelings through questioning and 
the impact they are having on the individual; and (e) homework exercises (Jones-Smith, 2016a).

Rehabilitation counseling professionals interested in employing Cognitive Behavioral Therapy techniques into their counseling amongst persons with disabilities can draw upon the foundation built through the development of a caring, compassionate, and empathic relationship. Cognitive Behavioral Therapy is an approach that integrates components from other theories (Beck, 2011), and an essential beginning point is with the cultivation of a strong, trusting, and compassionate alliance with the individual served. A number of persons with disabilities may enter counseling or start the rehabilitation process feeling emotionally or mentally down-trodden; some may be so hurt or grief stricken that they don't yet recognize that which they think and feel or the ways in which negative thoughts and feelings influence them and their coping ability. The cultivation of an accepting and compassionate counseling relationship may be a way to initially demonstrate and model compassion to persons with disabilities and can serve as gateway for them to feel safe enough to explore their own functioning and barriers that prevent them from being compassionate towards themselves or others.

Goal setting is another way to address compassion and self-compassion as a part of the therapeutic process. Whilst the emphasis should not be on whether or not they achieve them perfectly, counselors can assist people in achieving forward movement towards them. Being accepting of imperfection and goal attainment is important because people who are highly critical, judgmental, and perfectionistic tend to demonstrate lower levels of self-compassion and may be more challenged in being able to calm and self-soothe when upset or distraught. Thus, rehabilitation counselors can collaboratively explore and work with individuals to determine if they report difficulty being overly critical or not being able to accept themselves as they are and as human beings who are imperfect (since all people are imperfect) (Neff, 2011). Further, rehabilitation counselors can explore with the people they serve to determine if they are interested in learning more about compassion and self-compassion as a coping strategy and as a means to help them self-regulate and soothe their negative thoughts and feelings.

Third, rehabilitation counseling professionals can use or infuse counseling exercises that facilitate peoples' understanding of the relationship between their thoughts, feelings, and behaviors. Rehabilitation counselors can promote personal awareness in a number of ways and the focus should be on the identification of techniques and strategies that work for each person. For example, rehabilitation counselors can explore and educate people about the said relationship between a person's thoughts, feelings, and behaviors; or they can use homework exercises. Homework may include journal writing, self-talk identification and monitoring strategies (Riggenbach, 2013), recognition of negative consequences when persons with disabilities listen to and internalize negative thoughts and feelings (Riggenbach, 2013), and recognition of negative thoughts and identification of whether or not they are compassionate or self-compassionate, just to name a few.

Fourth, rehabilitation counselors can gently and supportively encourage the exploration of how the interconnectedness of a person's thoughts, feelings, and behaviors are impacting the in- dividual (i.e., physical or internal symptomology, increased stress, feeling anxious or upset). Related, rehabilitation counselors can assist persons with disabilities in readily identifying within themselves if their thoughts, feelings, or behaviors are compassionate or self-compassionate, and strategies they might employ to help them be more compassionate and/or self-compassionate.

Finally, rehabilitation counseling professionals can use homework exercises to promote compassion and self-compassion. Whilst some of the aforementioned exercises may be used as a part of homework, rehabilitation counselors can also encourage the use and practice of other compassion-cultivation strategies as a part of the homework that occurs between sessions, particularly as they can aid in coping with negative thoughts and feelings. For instance, persons with disabilities can further practice self-calming, self-soothing, and behavioral practices which are often promoted as a part of self-compassion interventions (i.e., breathing, meditational practices, body scan exercises, practicing gratitude, loving-kindness activities; see Germer, Neff, Becker, \& Hickman, 2015) or counseling approaches that infuses components of Eastern philosophy and medicine (i.e., mindfulness; see Linehan, 2015; McKay, Wood, \& Brantley, 2007; Segal, Williams, \& Teasdale, 2002). Further, rehabilitation counselors can encourage persons with disabilities by learning more about self-compassion and compassion through biblio-therapy as learning about the topic may be of great value before deciding on specific techniques (see Germer, 2009; Gilbert, 2009; Neff, 2011). Books about compassion and self-compassion provide not only information about these constructs, but many provide realistic and doable exercises throughout that can be practiced as part of everyday life.

\section{Self-Compassion: An Adjunct and Integrative Approach}

Compassion and self-compassion are relatively new to counseling, psychology, education, medicine, and the helping professions (Stuntzner, 2014) from the perspective of them being actively and directly included into counseling approaches as skills that can be taught and cultivated within the people served. Historically, it may have been assumed that compassion was a part of the counseling relationship, particularly with the emphasis on specific aspects such as empathy, unconditional positive regard, and client acceptance. However, it is important for rehabilitation counseling professionals to understand that the presence of compassion in the counseling relationship is not the same thing as modeling, teaching, and assisting persons with disabilities in actively cultivating and integrating it into their own lives or as a healthy coping strategy. Teaching persons with disabilities about compassion and self-compassion cultivation is an active and intentional process; for many people it becomes a way of life, especially as they discover the multiple benefits and ways it improves their lives (Halifax, 2011; Gilbert et al., 2011; Neff, 2003; Neff et al., 2007a; Neff \& Pommier, 2012; Makranski, 2012; Pauley \& McPherson, 2010; Stone, 2008; Terry \& Leary, 2011, The Dali Lama, 2003, 2011).

Self-compassion is the ability to accept oneself, one's imperfections and flaws and to extend oneself positive qualities such as love, support, genuine warmth and comfort when one is experiencing emotional, mental, psychological, or physical pain (Neff, 2012). According to Neff (2003), self-compassion is a skill 
or a way of being people can use to be kinder to themselves when life does not turn out as planned, and as a means to help them accept their fallibilities and imperfections, because no one is perfect. She also states that self-compassion can be used to help people confront their challenges and difficulties rather than avoiding or suppressing them, and it is through this process of sitting with their thoughts, experiences, and imperfections that people learn to soothe themselves and accept what is without being harmful to themselves.

Compassion is related to self-compassion in that it refers to the person's ability to extend love, kindness, peace, warm thoughts, tolerance and generosity toward others (i.e., a friend, relative, or a stranger) rather than towards oneself (The Dali Lama, 2003; Makranski, 2012; Neff, 2011). Germer and Neff (2013) indicate that people often find it easier to extend compassion towards others than themselves and that people who are highly self-compassionate find it much easier to be compassionate towards others because their own personal needs are met; thus, they have an abundance to extend to others.

Self-compassion can be approached and integrated into the counseling relationship in a number of ways. Self-compassion cultivation strategies can be included as a part of Person-centered or Cognitive Behavioral Therapy. However, self-compassion skills can also be developed through the use of self-compassion interventions and techniques (i.e., Mindfulness Self-Compassion Training; Germer et al., 2015), drawn from other theoretical approaches (i.e., mindfulness; Linehan, 2015) or compassion-oriented therapies (Loving Kindness Meditation, LKM; Frederickson, Cohn, Coffey, Pek, \& Finkel, 2008), Compassion Focused Therapy (CFT; Gilbert, 2010; Gilbert \& Proctor, 2006), Mindful-

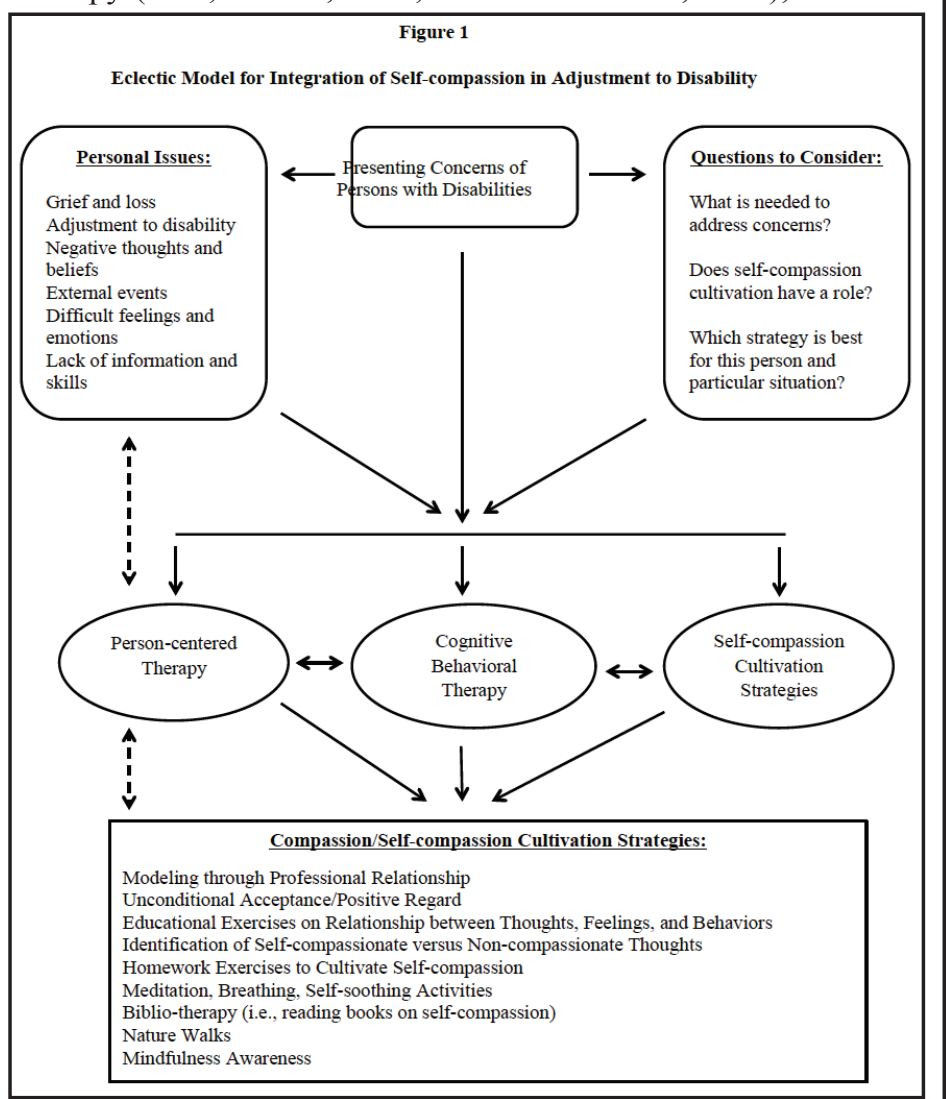

ness-Based Cognitive Therapy (MBCT; Segal et al., 2002), and individually tailored compassion cultivation techniques specifically chosen for the individual.

Specific strategies and activities to build and strengthen self-compassion are numerous and may include meditation (i.e., Extending Loving Kindness to Ourselves, Giving and Receiving Compassion; Germer et al., 2015), breathing deep breaths, writing a compassionate letter to oneself (Gilbert, 2009), locating and practicing loving and self-soothing mantras that can be practiced when a person experiences personal and emotional pain (Germer et al., 2015), participating in a mindfully aware nature walk, praying, spending time in nature or doing something you love (i.e., petting and playing with the dog, going on a spiritual retreat; Linehan, 2015; McKay et al., 2007), practicing radical acceptance techniques as a part of a person's cognitive coping statements (McKay et al., 2007), identifying and engaging in pleasurable activities which also have a calming effect (McKay et al., 2007), allowing oneself to be curious about thoughts and feelings experienced without judgment (Jones-Smith, 2016a; Neff, 2011), reading books, and trying application exercises pertaining to compassion and self-compassion (see Germer, 2009; Gilbert, 2009; Stuntzner, 2016). Rehabilitation counseling professionals interested in using self-compassion cultivation strategies are encouraged to identify and determine with persons with disabilities approaches and techniques which are deemed most useful to them and their needs.

\section{An Eclectic Approach to Grief, Loss, and Change Following Disability}

Another way to conceptualize and approach the teaching and cultivation of self-compassion and compassion-oriented skills is through the use of an integrated model that infuses self-compassion into the grief, loss, and adjustment to disability process. Figure 1 is provided to help illustrate the ways self-compassion can be considered and utilized in this process. In this model, rehabilitation counseling professionals may begin by listening to the presenting concerns of persons with disabilities. At this juncture, rehabilitation counselors may simultaneously consider the personal issues and coping concerns persons with disabilities are experiencing while they conceptualize questions and consider the role and applicability of self-compassion and compassion cultivation as a means to assist persons with disabilities in working through negative thoughts, feelings, and experiences.

Depending on the person's individualized situation, level of emotional pain, grief or loss, personality, and needs, rehabilitation counselors may determine which therapeutic approach or combination of approaches may be most effective in assisting the person in learning about self-compassion and its therapeutic qualities and relevance. For example, rehabilitation counselors may discover that compassion and self-compassion cultivation is most suited in the identified techniques associated with Person-centered Therapy. Others may realize the people they work with need and respond to a more directive approach such as Cognitive Behavioral Therapy and the enlistment of exercises such as understanding the relationship between a person's thoughts, feelings, and behaviors, or through biblio-therapy and homework exercises. Still, other rehabilitation counselors may find it most beneficial to 
fully embrace specific self-compassion cultivation strategies (i.e., meditation, breathing, nature walks, self-soothing activities, personal mantras to calm oneself when upset) rather than focus on a particular theoretical framework. Some may use a combination of all three either in the order presented as it may be viewed that each of these approaches build upon the other. In this example, rehabilitation counselors may elect to start the compassion-cultivation process with the development of a caring and unconditionally accepting professional relationship; one that clearly models compassion in the eyes of the individual being served. Later on in the counseling process, professionals may employ techniques and strategies such as those mentioned through the guise of Cognitive Behavioral Therapy followed by the teaching, cultivation, and practice of self-compassion strategies that may be solicited from other therapeutic approaches. Finally, some professionals may simultaneously draw from all three and present the skills and exercises as deemed most relevant and beneficial to the individual.

Regardless of the specific path chosen to present, teach, and encourage self-compassion and related compassion-cultivation strategies, it is essential to understand that there is more than one way to approach it (Germer et al., 2015). At this particular juncture, there is not one 'identified' right way to teach and cultivate self-compassion, particularly since it is relatively new amongst Westernized psychology and counseling fields. Rehabilitation counseling professionals may need to use their professional knowledge, understanding, and clinical skills to consider when in the counseling process it is most beneficial to introduce self-compassion skills as well as how to identify those that may be most relevant and meaningful to the individual as a part of the healing process. Further, it is recommended that rehabilitation counselors periodically "check in" and ask people how self-compassion skills are influencing or addressing the originally presented concerns. This suggestion is illustrated in Figure 1 as a final component of implementing the skills learned to help assess whether or not those selected are helping or if other self-compassion and compassion-cultivation techniques need to be considered.

\section{Connecting the Research to Adjustment to Disability}

Compassion and self-compassion offers many benefits. Many have been supported by empirical research and appear to have relevance to the hurt, pain, and feelings of grief and loss experienced and to the adjustment to disability needs of persons with disabilities. In an effort to assist rehabilitation counseling professionals in understanding the potential application and relevance of these two constructs to the emotional healing and adjustment to disability process Table 1 has been provided to illustrate a full review.

Compassion for others has been found to have many benefits and several of these are similar to the experiences or feelings of persons with disabilities. For instance, compassion can help people feel connected and less isolated (Halifax, 2011; Neff et al., 2007a; Walsh-Frank, 2012) given the fact they begin to understand that they are not alone in their experience of feeling pain (Terry \& Leary, 2011). Compassion helps people become more open-minded, less judgmental, and accepting of oneself and others (Terry
\& Leary, 2011). Additionally, it has a strong relationship to the alleviation of personal hurts and negative feelings such as anger, fear, and shame (Gilbert et al., 2011; Makranski, 2012; Stone, 2008), and in reducing self-centeredness (The Dali Lama, 2003) and self-critical thoughts (Gilbert et al., 2011). Positive traits are also associated with compassion, and some of these include forgiveness (Stone, 2008) and the ability to develop inner strength and courage (The Dali Lama, 2003; 2011).

Each of these benefits can be used to help persons with disabilities cope with grief and loss and improve their coping. For example, people who feel more connected to others because of their hurt and pain may feel less alone and socially isolated. Persons with disabilities who learn to embrace compassion may experience less anger, fear, shame, or other negative emotions which may translate into better coping and less negative feelings. Additionally, it is a well-known fact that people cannot experience love, kindness, and compassion and negative feelings such as anger or fear, simultaneously. Usually, one or the other is present, at any one time. Therefore, when persons with disabilities embrace life from a more compassionate standpoint, there is no room for negativity.

Similar to its counterpart, self-compassion has begun to demonstrate many positive outcomes for people who have or use it as a skill for living. Self-compassion helps people feel connected to others (Neff, 2003), comply with their suggested medical regime (Terry \& Leary, 2011), facilitate resilience (Leary, Tate, Adams, Allen, \& Hancock, 2007; Neff, K. D., Hsieh, Y, \& Djitterat, 2005), and is associated with forgiveness (Neff \& Pommier, 2012). Further, self-compassion is found to be a helpful skill in improving life satisfaction (Neff, 2003) and promoting a sense of optimism (Neff, Rude, \& Kirkpatrick, 2007) and in assisting people to find

\begin{tabular}{|c|c|c|}
\hline \multicolumn{3}{|c|}{$\begin{array}{l}\text { Table } 1 \\
\text { Connection between Compassion and Adjustment to Disability }\end{array}$} \\
\hline Compassion & Self-Compassion & Adjustment to Disability \\
\hline Sense of Connectedness & Feeling Connected & Lack of Social Isolation \\
\hline Promotes Self-Acceptance & & Better Self-image \\
\hline Helps People Forgive & Correlated with Forgiveness & Forgive Self and Others \\
\hline Heals Emotional Hurts & Reduces Anxiety, Depression & Better Emotional Coping \\
\hline Develops Inner Strength & Facilitates Resilience & Resilience/Coping Skills \\
\hline Reduces Anger, Fear, and Shame & Less Self-blame & Fewer Negative Feelings \\
\hline \multirow[t]{5}{*}{$\begin{array}{l}\text { Decreases Self-centeredness } \\
\text { and Self-criticism }\end{array}$} & Decreases Self-criticism & $\begin{array}{l}\text { Less Focus on Self and } \\
\text { Negativity }\end{array}$ \\
\hline & Reduces Stress & $\begin{array}{l}\text { Decreased Stress and } \\
\text { Anxiety }\end{array}$ \\
\hline & $\begin{array}{l}\text { Compliance with Medical } \\
\text { Regime }\end{array}$ & $\begin{array}{l}\text { Potential of Improved } \\
\text { Health \& Functioning }\end{array}$ \\
\hline & $\begin{array}{l}\text { Improves Life Satisfaction } \\
\text { and Optimism }\end{array}$ & Affects Outlook on Life \\
\hline & Creates a Sense of Meaning & $\begin{array}{l}\text { Purpose in Life/Meaning } \\
\text { of Disability }\end{array}$ \\
\hline \multicolumn{3}{|c|}{$\begin{array}{l}\text { Note: Citations and references for compassion and self-compassion are cited in the text under the } \\
\text { heading: Connecting the Research to Adjustment to Disability. Other research variables may also } \\
\text { apply but these were selected for compassion and self-compassion to help further clarify how } \\
\text { much of the research to-date may be used to understand the ways they may positively impact } \\
\text { adjustment to disability. }\end{array}$} \\
\hline
\end{tabular}


meaning or purpose in their experiences (Pauley \& McPherson, 2010).

Persons with disabilities who learn to use and apply self-compassionate techniques within their coping process may potentially realize they are not alone in their experiences, learn to forgive themselves or others for the transgression committed, develop a higher sense of purpose or meaning because of their disability, and improve their coping skills through the ability to demonstrate greater resiliency. As they learn to be kinder and more loving towards themselves, they may also discover they have an improved outlook on life or an increased willingness to practice self-care and to take good care of their personal health.

Self-compassion can also be viewed in terms of how it may help persons with disabilities reduce negative thoughts and feelings. Acknowledging this potential connection is important because research has established that poor coping often entails the use and practice of negative thoughts and feelings. Therefore, based on the research which demonstrates the utility of self-compassion in reducing negative thoughts and feelings (i.e., anxiety, depression, self-blame, self-critical thoughts; (Leary et al., 2007; Neff, 2003; Neff et al., 2005; Neff et al., 2007a; Terry \& Leary, 2011), it is plausible to consider the vitality of it in helping people with disabilities learn to improve their mental and emotional coping abilities.

\section{Implementation of Compassion and Self-compassion in the RC Relationship}

An important issue not yet addressed is that of professionals' knowledge and personal use of compassion and self-compassion strategies throughout their life. As with any new skill, the better professionals understand and apply it to their own life, the more likely they will be proficient in modeling and demonstrating it to persons with disabilities. Related and also important is the pointin-time at which to introduce compassion and/or self-compassion into the rehabilitation counseling relationship. To date, very little information exists to assist rehabilitation counseling professionals in determining how best to infuse these constructs into the rehabilitation process (Stuntzner, 2014). Therefore, a key element in fully understanding the value of compassion and self-compassion as a part of the rehabilitation counseling process is for professionals to learn as much as they can about it so these skills can be effectively applied and integrated in their work amongst persons with disabilities.

Rehabilitation counselors can increase their own personal and formalized knowledge any number of ways. As indicated earlier, there are a growing number of compassion-oriented approaches to help people and professionals understand these concepts and how to cultivate and integrate them into their own lives and into the lives of the people they counsel. Some possible approaches include Compassion Focused Therapy (CFT; Gilbert, 2010), Mindful Self-Compassion Training (MSC; Germer et al., 2015), and Mindfulness-based Stress Reduction (MBSR; Kabat-Zinn, 1982). Rehabilitation counseling professionals can learn more about these approaches and access some additional information about classes, trainings, and retreats through websites such as: www.compassionatemind.co.uk (i.e., CFT), http://www.mind-
fullivingprograms.com/whatMBSR.php (i.e., MBSR), and www. self-compassion.org (i.e., MSC). Additionally, counselors may review compassion-oriented trainings at UCLAs Mindful Awareness Research Center, http://marc.ucla.edu/body/cfm?id=29, or at Stanford's Center for Compassion and Altruism Research and Education, www.care.stanford.edu, which holds classes, workshops, or trainings to become teachers of mindfulness or self-compassion.

Finally, some rehabilitation counseling professionals may decide to address these concepts more informally or through the process of knowing what is available in the surrounding community. Those who regularly meditate or practice meditational and compassion-oriented practices, throughout their daily lives, may find it easy to conceptualize and adapt approaches they know to the needs of the people they serve. Counselors may choose to apply compassion-oriented techniques to groups or in an individualized manner depending on the geographical location and interest generated from the surrounding area. Others may find it helpful to locate mindfulness-based groups or to learn about what is available at local hospitals, especially given the fact that compassionate-health care is also becoming more popular in medical arenas.

Regardless of the exact approaches used, it is important for counselors and persons with disabilities to be aware that the practice of compassion and self-compassion may not always be easy, nor do the benefits always arrive quickly. Rather, the practice of self-compassion, in particular, may require regular practice and a conscious effort before it feels more comfortable and automatic (Gilbert, 2009), especially given the fact that society doesn't give people permission to be kind and tender with themselves in the same ways they may be to another (Germer \& Neff, 2013). Many people, disability or no disability, have to learn how to be kind, gentle, and compassionate towards their own hurts and often find it easier to focus on other people than themselves (Germer \& Neff, 2013).

\section{Implementation for Rehabilitation Counseling Professionals}

Rehabilitation counseling professionals interested in infusing compassion into the adjustment to disability process can begin by learning more about self-compassion and compassion-cultivation strategies and exploring the numerous resources and trainings presented throughout. Such trainings can assist rehabilitation counseling professionals in learning about self-compassion and its application towards themselves and those they serve as well as become more comfortable with the idea of meditation, self-kindness, and generosity. The more rehabilitation counselors understand and apply it to themselves and their lives, the easier it will be to convey it to others.

Beyond the learning and cultivation of self-compassion is the notion of how to assess the adjustment to disability process of persons with disabilities in relation to the integration of compassion for oneself and others. Rehabilitation counseling professionals can always refer to the schematic framework presented in Figure 1. From this perspective, counselors can informally assess or check-in to determine which of the personal issues (i.e., cognitive beliefs, external messages, feelings and emotions in relation to disability) someone is having difficulty coping with and addressing. In addition, rehabilitation counselors may find it helpful 
to be mindful of the presence of critical or judgmental thoughts, negative emotions, personal berating associated with perfectionism, self-evaluation behaviors (i.e., perceives self as good or bad), internal strife rather than peace and kindness (Neff, 2011), or other thoughts and emotional behaviors which may indicate the person is having difficulty in being self-soothing or kind to oneself. Counselors who observe the presence of these "behavioral indicators" can be alerted to the idea that learning self-compassion and compassionate-based skills may be of value. Once it has been determined that the individual may benefit from being exposed to and learning self-compassion and compassion-oriented skills as a part of the grief, loss, and adjustment to disability process, rehabilitation counselors can then work collaboratively with the individual to determine the best counseling or skill building approach for meeting this goal.

Rehabilitation counseling professionals may also find it helpful to periodically ask for feedback from the people they serve. Following the development and practice of compassionate and self-compassionate techniques (i.e., letter writing, meditation, doing something nice for oneself when upset; Germer et al., 2015; Gilbert, 2009; Neff, 2011), counselors may inquire about the utility and value or observable personal change noted by the individuals learning this skill. Professional solicitation of client feedback can help rehabilitation counseling professionals better understand which skills and exercises work most of the time versus not at all and where changes might be warranted. In addition, following some conscious practice of compassion-based skills, rehabilitation counselors may enquire about the ways these techniques have helped improve peoples' functioning such as those listed in Table 1 (i.e., forgiving of self or others, experience fewer negative emotions).

\section{References}

Beck, A. T. (2005). The current state of cognitive therapy: A 40 year retrospective. Archives of General Psychiatry, 62(9), 953-959.

Beck, A. T., Rush, A. J., Shaw, B. F., \& Emery, G. (1979). Cognitive therapy of depression. New York: Guilford Press.

Beck, J. (2011). Cognitive therapy: Basics and beyond ( $2^{\text {nd }}$ ed.). New York: Guilford PressBruce, T., Spiegel, D., \& Hegel, M. (1999). Cognitive-behavioral therapy helps prevent relapse and reoccurrence of panic disorder following alprazolam discontinuation: A long-term follow-up on the Peoria and Dartmouth studies. Journal of Consulting and Clinical Psychology, 67, $151-156$.

Buckelew, B., Baumstark, M., Frank, P., \& Hewett, F. (1990). Adjustment following spinal cord injury. Rehabilitation Psychology, 35, 101-109.

Cott, C. A. (2004). Client-centered rehabilitation: Client perspectives. Disability and Rehabilitation, 26(24), 1411-1422.

Cutrona, C. E. (1993). Causal attributions and perinatal depression. Journal of Abnormal Psychology, 92, 161-172.

Dali Lama (2011). How to be compassionate: A handbook for creating inner peace and a happier world. New York: Atria Paperback.
Dali Lama (2003). The compassionate life. Somerville, MA: Wisdom Publications, Inc.

Elders, M. A. (1995). Theory and present thinking in bereavement. Issues in Psychoanalytic Psychology, 17, 67-83.

Elliott, R., Watson, J., Goldman, R. N., \& Greenberg, L. S. (2004). Learning emotion-focused therapy: The process of experiential approach to change. Washington, DC: American Psychological Association.

Enright, R. D. (2001). Forgiveness is a choice: A step-by-step process for resolving anger and restoring hope. Washington, DC: American Psychological Association.

Enright, R. D., Rique, J., \& Coyle, C. T. (2000). The Enright Forgiveness Inventory user's manual (EFI). Madison, WI: The International Forgiveness Institute.

Feldman, C., \& Kuyken, W. (2011). Compassion in the landscape of suffering. Contemporary Buddhism, 12(1), $143-155$.

Frederickson, B. L., Cohn, M., Coffey, K. A., Pek, J., \& Finkel, S. A. (2008). Open hearts build lives: Positive emotions, induced through loving kindness meditation, build consequential personal resources. Journal of Personality and Social Psychology, 95, 1045-1062.

Germer, C. K. (2009). The mindful path to self-compassion: Freeing yourself from destructive thoughts and emotions. New York: The Guilford Press.

Germer, C. K., \& Neff, K. D. (2013). Mindfulness Self-compassion Training (MSC). November 20 - 24. Santa Monica, CA: Insight LA.

Germer, C. K., Neff, K., Becker, M., \& Hickman, S. (2015) Mindful self-compassion teacher's guide. San Diego, CA: UCSD Center for Mindfulness, Mindfulness-Based Professional Training Institute.

Gilbert, P. (2010). Compassion focused therapy. New York: Routledge.

Gilbert, P. (2009). The compassionate mind: A new approach to life's challenges. Oakland, CA: New Harbinger Publications, Inc.

Gilbert, P., McEwan, K., Matos, M., \& Rivis, A. (2011). Fears of compassion: Development of three self-report measures. Psychology of Psychotherapy: Theory, Research, and Practice, 84, 239-255.

Gilbert, P., \& Proctor, S. (2006). Compassionate mindtraining people with high shame and self-criticism: Overview and pilot study of a group therapy approach. Clinical Psychological Psychotherapy, 13, 353-379.

Goffman, E. (1963). Stigma: Notes on the management of spoiled identity. London: Penguin Books.

Grover, J. (2015). Operationalizing compassion in the VR process. Journal of Applied Rehabilitation Counseling, 46(3), 3 -14 .

Halifax, J. (2011). The precious necessity of compassion. Journal of Pain and Symptom Management, 41(1), 146-153.

Jones-Smith, E. (2016a). Cognitive approaches to psychotherapy. Theories of counseling and psychotherapy: An integrative approach (pp. 159-208). Thousand Oaks, CA: Sage Publications Inc. 
Jones-Smith, E. (2016b). Person-centered therapy. Theories of counseling and psychotherapy: An integrative approach (pp. 261 -284). Thousand Oaks, CA: Sage Publications Inc.

Kabat-Zinn, J. (1982). An outpatient program in behavioral medicine for chronic pain patients based on the practice of mindfulness meditation: Theoretical considerations and preliminary results. General Hospital Psychiatry, 4, 3342.

Leary, M. R., Tate, E. B., Adams, C. E., Allen, A. B., \& Hancock, J. (2007). Self-compassion and reactions to unpleasant self-relevant events. The implications of treating oneself kindly. Journal of Personality and Social Psychology, 92, 887-904.

Linehan, M. M. (2015). DBT skills training manual ( $2^{\text {nd }}$ ed.). New York: Guilford.

Livneh, H., \& Antonak, H. (1997). Psychosocial adaptation to chronic illness and disability. Gathersburg, MA: Aspen Publishing.

Makranski, J. (2012). Compassion in Buddhist psychology. In C. I . Germer and R. D. Siegel (Eds.) Wisdom and compassion in psychotherapy: Deepening mindfulness in clinical practice (pp. 61-74). New York: Guilford Press.

McKay, M., Wood, J. C., \& Brantley, J. (2007). The dialectical behavior therapy skills workbook: Practical DBT exercises for learning mindfulness, interpersonal effectiveness, emotional regulation, and distress tolerance. Oakland, CA: New Harbinger Publications Inc.

Mindful Living Programs (2014). Retrieved on February 20, 2014 from: http://mindfullivingprograms.com/index.php

Murray, J. A. (2001). Loss as a universal concept: A review of the literature to identify common aspects of loss in diverse situations. Journal of Loss and Trauma, 6, 219-241.

Neff, K. (2003). Self-compassion: An alternative conceptualization of a healthy attitude toward oneself. Self and Identity, 2, 85-101.

Neff, K. D. (2009). Self-compassion: A healthier way of relating to yourself. Retrieved on August 11, 2013 from: www. self-compassion.org.

Neff, K. (2011). Self-compassion: Stop beating yourself up and leave insecurity behind. New York, NY: Harper Collins Publishers.

Neff, K. (2012). The science of self-compassion. In C. K. Germer \& R. D. Siegel (Eds.) Wisdom and compassion in psychotherapy: Deepening mindfulness in clinical practice (pp. 79-92). New York: Guilford Press.

Neff, K. D., Hsieh, Y., \& Djitterat, K. (2005). Self-compassion, achievement goals, and coping with academic failure, Self and Identity, 4, 263-287.

Neff, K. D., Kirkpatrick, K. L., \& Rude, S. S. (2007a). Self-compassion and adaptive psychological functioning. Journal of Research in Personality, 41, 139-154.

Neff, K. D., \& Pommier, E. (2012). The relationship between self-compassion and other-focused concern among college undergraduates, community adults, and practicing meditators, Self and Identity. doi: 10.1080./15298868.2011.
Neff, K. D., Rude, S. S., \& Kirkpatrick, K. L. (2007b). An examination of self-compassion in relation to positive psychological functioning and personality traits. Journal of Research in Personality, 41, 908-916.

Neimeyer, R. A. (1999). Narrative strategies in grief therapy. Journal of Constructivist Psychology, 12, $65-85$.

Nielson, W. R., \& MacDonald, M. R. (1998). Attributions of blame and coping following spinal cord injury: Is self-blame adaptive? Journal of Social and Clinical Psychology, 7, 163-175.

Park, C.L. (2010). Making sense of the meaning literature: An integrative review of meaning making and its effects on adjustment to stressful life events. Psychological Bulletin, 136(2), 257-301.

Parkes, C. M. (1988). Bereavement as a psychosocial transition: Processes of adaptation to change. Journal of Social Issues, 44(3), 53-65.

Pauley, G., \& McPherson, S. (2010). The experience and meaning of compassion and self-compassion for individuals with depression and anxiety. Psychology and Psychotherapy: Theory, Research, and Practice, 83, 129-143. DOI: 10.1348/147608309X471000

Raphael, B. (1984). The anatomy of bereavement: A handbook for the caring professions. London: Hutchinson.

Reeve, D. (2002). Negotiating psycho-emotional dimensions of disability and their influence on identity construction. Disability and Society, 17, 493-508.

Riggenbach, J. (2013). The CBT toolbox: A workbook for clients and clinicians. Eau Claire, WI: PESI Publishing and Media.

Scofield, M. E., Pape, D. A., McCracken, N., \& Maki, D. R. (1980). An ecological model for promoting acceptance of disability. Journal of Applied Rehabilitation Counseling, 11, 183-187.

Segal, Z., Williams, M., \& Teasdale, J. (2002). Mindfulness-Based cognitive behavioral therapy for depression: A new approach to preventing relapse. New York: Guildford Press.

Siller, J., Chipman, A., Ferguson, L. T., \& Vann, D. (1967). Attitudes of the nondisabled toward the physically disabled. In J. Siller \& K. R. Thomas (1995), Essays and research on disability (pp. 21-30). Athens, GA: Elliott and Fitzpatrick.

Smart, J. (2009). Disability, society, and the individual (2 ${ }^{\text {nd }}$ ed.). Austin, TX: PRO-ED.

Spandler, H., \& Stickley, T. (2011). No hope without compassion: The importance of compassion in recovery-focused mental health services. Journal of Mental Health, 20(6), 555566.

Stanford's Center for Compassion, Altruism Research, and Education (2014). Retrieved On February 20, 2014 from: www. ccare.stanford.edu.

Stone, D. (2008). Wounded healing: Exploring the circle of compassion in the helping relationship. The Humanistic Psychologist, 36, 45-51.

Stuntzner, S. (2016). Book Review: Gilbert (2009). The compassionate mind: A new approach to life's challenges. New 
Harbinger Publications, Inc. American Association of Integrative Medicine, March Issue.

Stuntzner, S. (2014). Compassion and self-compassion: Exploration of utility as essential components of the rehabilitation counseling profession. Journal of Applied Rehabilitation Counseling, 45(1), 37-44.

Stuntzner, S. (2012). Living with a disability: Finding peace amidst the storm. Ahmedabad, Gurat, India: Counseling Association of India.

Stuntzner, S. (2015). Resiliency and coping with disability: The family after. Ahmedabad, Gurat, India: Counseling Association of India.

Swett, E. A., \& Kaplan, S. P. (2004). Cognitive-behavioral therapy. In N. L. Berven, K. R. Thomas, \& F. Chan (Eds.) Counseling theories and techniques for rehabilitation health professionals (pp. 159-176). New York: Springer Publishing Company.

Teel, C. S. (1991). Chronic sorrow: Analysis of a concept. Journal of Advanced Nursing, 16, 1311-1319.

Tennen, H., \& Affleck, G. (1990). Blaming others for threatening events. Psychological Bulletin, 108, 209-232.

Terry, M. L. \& Leary, M. R. (2011). Self-compassion, self-regulation, and health. Self and Identity, 10(3), 352-362.

The Compassionate Mind Foundation (2014). Retrieved on February 20, 2014 from: www.compassionatemind.co.uk.

Trieschmann, R. (1980). Spinal cord injuries: Psychological, social, and vocational rehabilitation. New York: Demos.

Trieschmann, R. (1988). Spinal cord injuries: Psychological, social, and vocational rehabilitation $\left(2^{\text {nd }}\right.$ ed.). New York: Demos.

Tursi, M. M., \& Cochran, J. L. (2006). Cognitive-behavioral tasks accomplished in a person-centered relational framework. Journal of Counseling and Development, 84, 387 - 396.

UCLAs Mindful Awareness Research Center (2014). Retrieved on February 20, 2014 from: http://marc.ucla.edu/body. cfm?id=29.

Walsh-Frank, P. (2012). Compassion: An east-west comparison. Asian Philosophy, 6(1).

Wright, B. (1983). Physical disability: A psychosocial approach. Elmsford, NY: Permagon.

Dr. Susan Stuntzner PhD, LPC, LMHP, CRC, NCC, $D C C$ is the Director of Disability Services and Student Retention at Southwestern Oregon Community College. Communications regarding this article can be sent to her via email at: susan.stuntzner@socc.edu. 